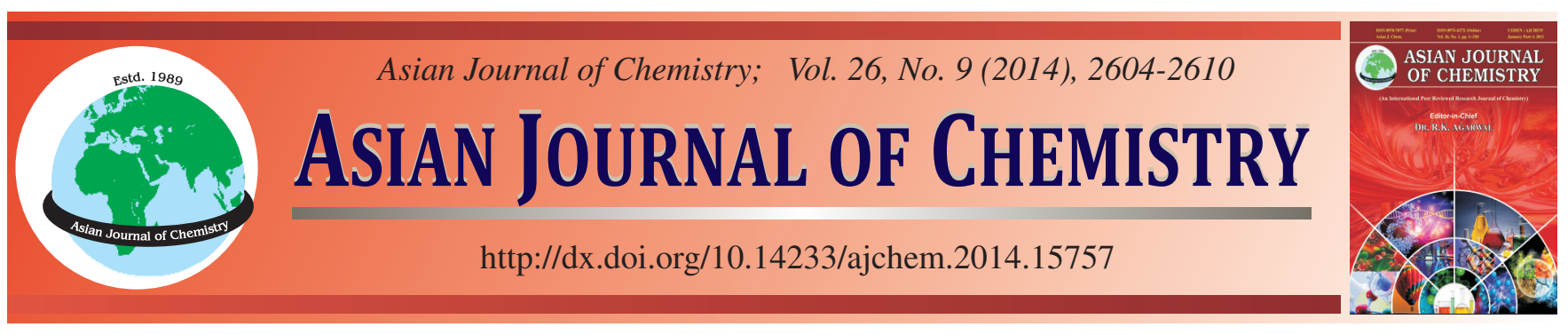

\title{
Development of Microparticulate Sustained Release Dosage Form of Emtricitabine: An Anti-HIV Drug
}

\author{
A. Fathima, B.N. Vedha Hari and D. Ramya Devi*
}

School of Chemical and Biotechnology, SASTRA University, Thanjavur-613 401 India

*Corresponding author: Fax: +91 4362 264120; Tel: +91 4362 264101/108; E-mail: ramya@ scbt.sastra.edu

\begin{abstract}
Emtricitabine is a nucleotide reverse transcriptase inhibitor used for HIV infections, with oral bioavailability of $93 \%$. Microparticles loaded with emtricitabine were formulated through ionotropic gelation method using sodium alginate as retardant polymer and calcium chloride as cross linker. The concentration of hydroxy propyl methyl cellulose and sodium alginate were varied as 50-300 mg and 100$900 \mathrm{mg}$ respectively using $3^{2}$ factorial design. The prepared microparticles were evaluated for particle size distribution (322.66 to 553.40 $\mu \mathrm{m})$, percentage yield (96.68-98.33\%) drug content (92.85-95.23\%) and drug entrapment efficiency (27.41 to 52.44 \%). The FT-IR spectroscopic analysis indicated the minimum drug polymer interaction during preparation. The stability and uniform dispersion of drug in the polymeric matrix was confirmed by DSC and XRD studies. The in vitro release profile indicated that increase in intensity of cross linking decreased the rate of drug release, with showed significant sustained release effect of the dosage form for more than $8 \mathrm{~h}$.
\end{abstract}

Keywords: Emtricitabine, Microparticles, Sodium alginate, Response surface methodology.

\section{INTRODUCTION}

Microparticles are solid rigid particles within the size ranging from 1 to $1000 \mu \mathrm{m}$. Depending upon the preparation of microparticles, the drug can be dissolved, entrapped, encapsulated using specific polymers ${ }^{1}$. Microparticles can be of matrix or reservoir type where drug is uniformly distributed in the system and provide a sustained release of the drug $^{2-3}$. Microparticles have the significance of providing prolonged action by circulating within system for expanded time schedule in addition to targeting particular organ, especially to deliver macromolecules like proteins, peptides and genes ${ }^{4-6}$.

The advantages of the microparticles are easy administration to deliver macromolecules by a variety of routes and effectively control the release of drugs over the periods ranging from few hours to months, because of effective protection of encapsulated drug against degradation ${ }^{7}$.

Emtricitabine is a nucleoside reverse transcriptase inhibitor (NRTI) and is an analogue of cytidine which is used in the treatment of HIV infections. The working principle of the drug is inhibition of reverse transcriptase and also lowering the quantity of viral load which can help to increase the activity of immune system. Emtricitabine is having a bioavailability of $93 \%$ and soluble in water, methanol and practically insoluble in dichloromethane. Emtricitabine is used in the combination with many other anti-viral drugs to treat HIV infections, commonly named as (HAART) $)^{8-10}$.
Alginate is naturally occurring polymeric substance obtained from brown algae, mainly consisting of blocks of mannuronic acid (M), guluronic acid $(\mathrm{G})$ and mannuronic guluronic acid $(\mathrm{MG})^{11}$, specially used for sustained delivery of drugs. Sodium alginate microparticles are prepared by ionic gelation technique which involves the addition of droplets of this polymer through small orifice into $\mathrm{CaCl}_{2}$ solution, where the calcium ions cross links the viscous gel polymer into rigid micro beads. This approach has certain black marks, to be precise, the tear drop shape of the microparticles produced, the limitation in reducing microparticle diameter and the complexity in manufacturing leveling up ${ }^{12,13}$. This proposed method can allow modifications in the size and dimension of the microparticles according to the orifice used i.e., the size of the needle ${ }^{14,15}$.

The intention of the present investigation is to formulate and check the quality parameters for the novel drug delivery intended for extended action via per oral route, namely microparticles of emtricitabine with sodium alginate by ionic - gelation method and also optimizing the formulation with statistical tool (RSM) to provide high entrapment efficiency, reducing dosing frequency and sustained release of the drug.

\section{EXPERIMENTAL}

Emtricitabine was presented by Matrix, Hyderabad, India. Hydroxyl propyl methyl cellulose (SD Fine Chem. Limited, 
Mumbai, India), sodium alginate (Chemspure, Chennai, India) were obtained from commercial sources. All the chemicals involved in this work were of laboratory analytical grade.

Formulation of emtricitabine microparticles: The block polymeric substance sodium alginate along with the mucoadhesive polymer mixture was dissolved in water to obtain a jelly solution into which the drug was dissolved or dispersed, which was then cross linked using calcium chloride by ionic gelation method ${ }^{16,17}$, to retard the release of the drug encapsulated or dispersed within its matrix. Trial formulations were prepared by this technique by varying the ratios of sodium alginate, being dissolved in required quantity of purified water. Next was the slow addition of mucoadhesive polymer into the alginate solution by way of nonstop mixing followed by sonication for 20 min to obtain a homogenous mixture. The drug substance Emtricitabine was added to the block polymermucoadhesive polymer combined mixture and stirred systematically until a clear solution was obtained. This complex solution was dropped using an insulin syringe into the $5 \%$ calcium chloride for cross linking the matrix. The cross linked particles were retained in the magnetic stirrer for $1 \mathrm{~h}$ with continuous stirring to ensure the curing process to be completed and also recover homogenous sized and shaped stiff microparticles. The microparticles were screened through filter or decant, rinsed constantly using deionized water and then kept for drying at $45^{\circ} \mathrm{C}$ for $12 \mathrm{~h}$. Nine trials planned by the factorial design by changing the ratio of block polymer and mucoadhesive polymer was scheduled in Table- 1 .

\begin{tabular}{|c|c|c|}
\hline \multicolumn{3}{|c|}{$\begin{array}{l}\text { TABLE-1 } \\
\text { FACTORIAL DESIGN FOR EMTRICITABINE } \\
\text { MICROPARTICLE FORMULATION }\end{array}$} \\
\hline Formulation code & $\begin{array}{l}\text { Hydroxy propyl methyl } \\
\text { cellulose (HPMC) }\end{array}$ & Sodium alginate \\
\hline EMF1 & -1 & 0 \\
\hline EMF2 & 0 & 0 \\
\hline EMF3 & 1 & 1 \\
\hline EMF4 & -1 & 1 \\
\hline EMF5 & -1 & -1 \\
\hline EMF6 & 1 & -1 \\
\hline EMF7 & 0 & 1 \\
\hline EMF8 & 0 & -1 \\
\hline EMF9 & 1 & 0 \\
\hline \multicolumn{3}{|c|}{$\begin{array}{l}\text { - HPMC (mg): }-1=50 ; 1=300 ; 0=175 \\
\text { - Sodium alginate (mg): }-1=100 ; 1=900 ; 0=500 \\
\text { - Drug (mg): } 100\end{array}$} \\
\hline
\end{tabular}

Estimation of drug content: An accurately weighed 10 $\mathrm{mg}$ or equivalent of drug portion of microparticles was taken in a $100 \mathrm{~mL}$ standard measurement flask and added with $5 \mathrm{~mL}$ of methanol to dissolve the drug and finally added phosphate buffer $\mathrm{pH} 7.4$ to ensure the standard volume ${ }^{17,18}$. After filtration and making apposite dilution, the solution was examined with UV-visible spectrophotometer (Perkin Elmer, USA) to estimate the amount of drug encapsulated in the microparticles.

Determination of percentage yield: The total amount of microparticles was weighed and the percentage yield was calculated depending upon the drug and the polymer quantity used in the formulation.

$\%$ Yield $=($ Practical yield $/$ Theoretical yield $) \times 100$
Calculation of drug entrapment level: A specific amount of microparticles containing drug were trampled to form powder and dissolved in $10 \mathrm{~mL}$ of phosphate buffer $\mathrm{pH} 7.4$ followed by sonication being done for $0.5 \mathrm{~h}$. The solution so obtained was then passed through Whatmann filter paper and the resultant filtrate was analyzed spectrophotometrically using UV-visible spectrophotometer (Perkin Elmer, USA) at $278 \mathrm{~nm}$. The percentage of drug entrapped within the microparticles shall be estimated using the formula,

Drug entrapment efficiency $=($ Experimental drug content / Theoretical drug content) $\times 100$

Detection of particle Size: The size of microparticles was measured through optical microscopy technique, with the help of compound light microscope (Khera instruments, Pvt Ltd, New Delhi) which was previously calibrated by eye piece micrometer. Small amount of microparticles were placed on clean dried glass slide $(5 \mathrm{~cm} \times 1 \mathrm{~cm})$ having thin film of oil layer (glycerin), placed on the platform and focused with 10X. Approximately 100 particles were measured for its diameter and the results were tabulated and mean was calculated ${ }^{17}$.

FT-IR spectroscopy analysis: A small quantity of the emtricitabine microparticles was ground along with IR grade dried potassium bromide which specifically avoids the unwanted light transmission and scattering problems. The mechanical die press is used to convert the powdered mixture into a thin disc through which the IR beam can be passed to determine the interaction of drug and excipients ${ }^{18-20}$.

In vitro drug release studies: An accurately weighed $10 \mathrm{mg}$ or its equivalent amount of emtricitabine microparticles was positioned in $200 \mathrm{~mL}$ of dissolution medium (phosphate buffer $\mathrm{pH} 7.4$ ), monitored at warmth condition of $37 \pm 0.5^{\circ} \mathrm{C}$ and stimulated at a rapidity of $75 \mathrm{rpm}$ using USP dissolution apparatus type I (basket). At different intervals of sampling moment, specified amount of liquid was sampled out from the dissolution jar and an identical volume of warm medium was replaced again to establish the sink situation. The liquids so obtained were screened and exposed at $230.4 \mathrm{~nm}$ in UVvisible spectrophotometer (Perkin Elmer, USA) against the phosphate buffer $\mathrm{pH} 7.4$ used as blank.

Differerential scanning calorimetric (DSC) analysis: The physicochemical compatibilities of the optimized formulations were analyzed by differential scanning calorimetry. The DSC thermograms of the crushed microparticles and the pure drug were obtained from a differential scanning calorimeter (Perkin Elmer, USA) with a thermal analysis data station system, computer and plotter interface. The device was previously calibrated using indium as standard. The samples $(2 \mathrm{mg})$ were analyzed at $30-220{ }^{\circ} \mathrm{C}^{18-20}$.

$\mathrm{X}$-Ray diffraction (XRD) analysis: Emitricitabine microparticles and the pure drug were experimented using Rigaku ultima III XRD analyzer with copper target, to identify their crystallinity nature. The set up of the instrument was $40 \mathrm{Kv}$ voltage with $30 \mathrm{~mA}$ current at room temperature and the samples being weighed down on the diffractometer and scanned at range of $2 \theta$ values from $3^{\circ}$ to $60^{\circ}$ at a scan rate of $0.05{ }^{\circ} \mathrm{C} / \mathrm{min}^{21-23}$.

Experimental analysis and statistical design: A $3^{2}$ factorial design was employed to design sustained release microparticles for Emtricitabine ${ }^{24-26}$. This design was suitable 


\begin{tabular}{cccc|ccc}
\hline \multicolumn{1}{c}{ TABLE-2 } \\
ACTUAL VALUES AND CODED VALUES OF EMTRICITABINE \\
- SODIUM ALGINATE MICROPARTICLES
\end{tabular}

for response surface of quadratic equations in which the two independent variables were hydroxy propyl methyl cellulose $\left(\mathrm{X}_{1}\right)$ and sodium alginate $\left(\mathrm{X}_{2}\right)$. The actual and coded levels of the design were represented in Table-2. The lower, intermediate and higher levels of each factor coded as $0,+1$ and -1 respectively. The dependent variables selected were drug entrapment efficiency $\left(\mathrm{Y}_{1}\right)$ and $\%$ drug release $\left(\mathrm{Y}_{2}\right)^{27-29}$.

\section{RESULTS AND DISCUSSION}

The practical yield obtained for the various trials were calculated with respect to its theoretical yield (Table-3), which ranged between 96.68 to $98.33 \%$. Percentage yield greater than $90 \%$ suggests that this technique shall be effectively adapted for the formulation of emtricitabine microparticles ${ }^{17}$.

Drug content: A wide variation in drug loading effect was observed for the experimented formulations with respect to changes in polymer : emtricitabine ratio. The percentage drug content of all the formulations was in the range of 92.85$95.23 \%$ (Table-3). The total content of the formulation remained within the required limits, which signify the presence of unmodified drug in the developed formulation ${ }^{18}$.

Drug entrapment efficiency: The percentages of encapsulation of all the formulation were in the range of 27.41 to $52.44 \%$ (Table-3). The change in encapsulation efficiency observed between all the formulations was due to the difference in the proportion of polymer used. With reference to the results, it was clear that by rising the quantity of polymer with respect to the drug, the entrapment level can be elevated.

Particle size: The dimensions of the microparticles of emtricitabine were analyzed by optical microscopy (Fig. 1). All the formulation of Emtricitabine microparticles showed regular size divisions. The particle size was found to be within the range of 322.66 to $553.40 \mu \mathrm{m}$ (Table-3). Even though the
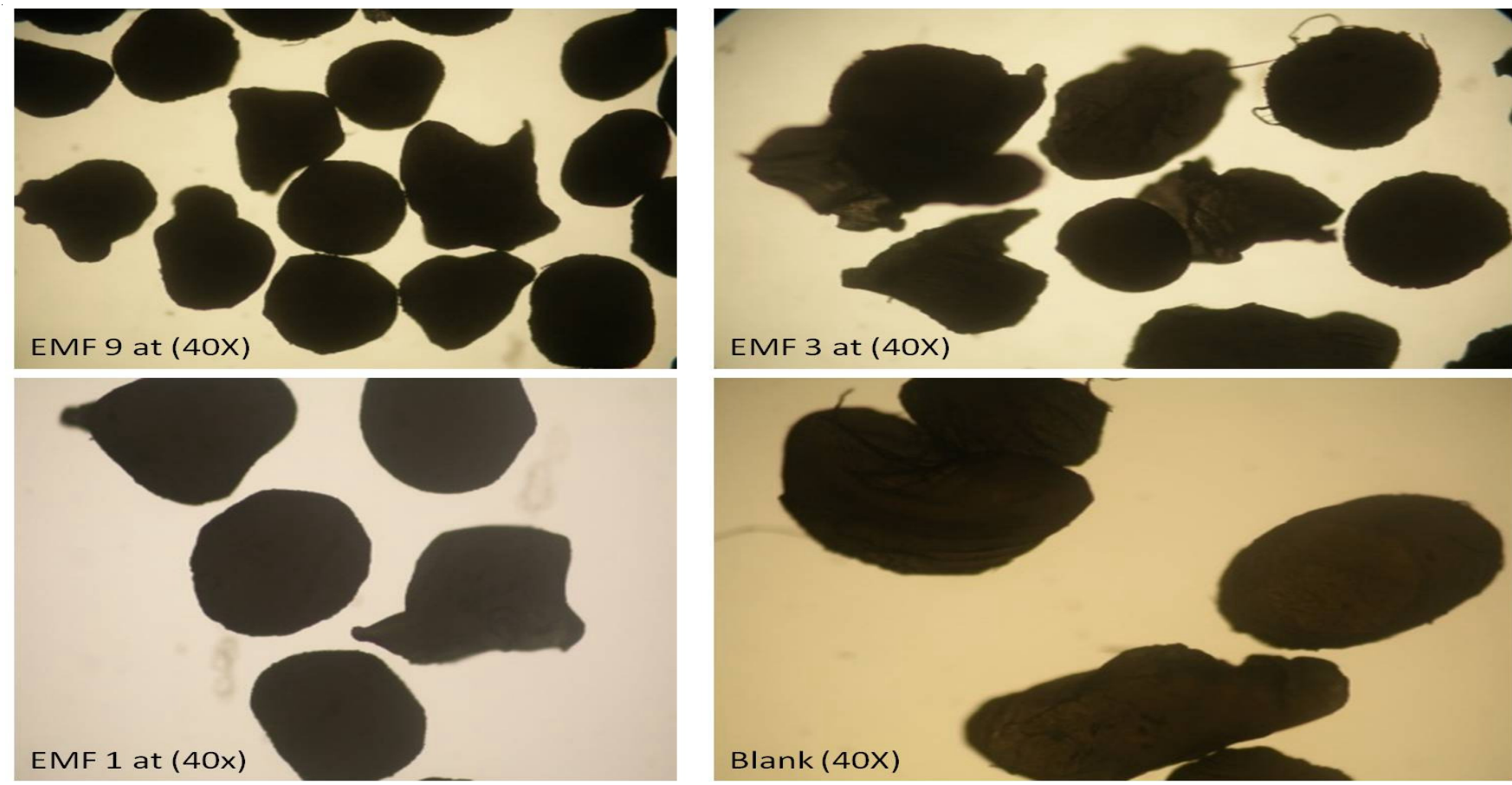

Fig. 1. Optical microscopic images of Emtricitabine-sodium alginate microparticles

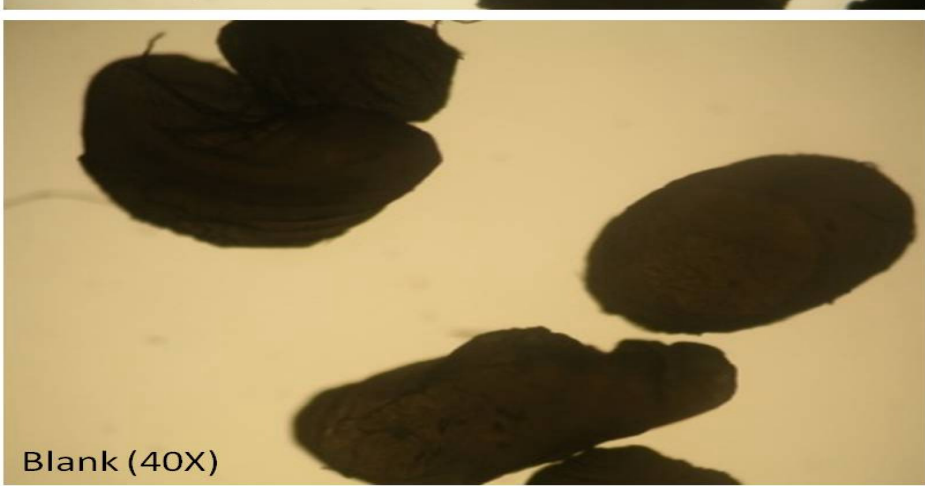

TABLE-3

COMPARATIVE EVALUATION OF PHYSICAL PARAMETERS OF EMTRICITABINE MICROPARTICLES

\begin{tabular}{cccccccc}
\hline S. No. & Formula code & $\begin{array}{c}\text { Drug : } \\
\text { polymers ratio }\end{array}$ & Particle size $(\mu \mathrm{m})$ & $(\%)$ yield & Drug content $(\%)$ & $\begin{array}{c}\text { Drug entrapment } \\
\text { efficiency }(\%)\end{array}$ & $\begin{array}{c}(\%) \text { Drug } \\
\text { release at } 8^{\text {th }} \mathrm{h}\end{array}$ \\
\hline 1 & EMF1 & $1: 0.5: 5$ & $553.40 \pm 23.1$ & 98.33 & $95.23 \pm 0.59$ & $52.44 \pm 0.63$ & $79.77 \pm 0.88$ \\
2 & EMF2 & $1: 1.75: 5$ & $330.34 \pm 16.2$ & 97.16 & $93.16 \pm 0.89$ & $42.50 \pm 0.75$ & $73.45 \pm 0.69$ \\
3 & EMF3 & $1: 3: 9$ & $400.95 \pm 56.9$ & 98.07 & $94.07 \pm 0.75$ & $27.41 \pm 0.64$ & $67.66 \pm 0.55$ \\
4 & EMF4 & $1: 0.5: 9$ & $322.66 \pm 8.08$ & 97.23 & $93.23 \pm 0.66$ & $35.66 \pm 0.62$ & $79.27 \pm 0.77$ \\
5 & EMF5 & $1: 0.5: 1$ & - & - & - & - & - \\
6 & EMF6 & $1: 3: 1$ & - & - & - & - & $70.56 \pm 0.99$ \\
7 & EMF7 & $1: 1.75: 9$ & $353.22 \pm 33.4$ & 96.68 & $92.85 \pm 0.54$ & $31.68 \pm 0.86$ & - \\
8 & EMF8 & $1: 1.75: 1$ & - & - & - & - & $68.36 \pm 0.58$ \\
9 & EMF9 & $1: 3: 5$ & $340.65 \pm 30.9$ & 97.07 & $93.07 \pm 0.98$ & $42.56 \pm 0.91$ & \\
\hline
\end{tabular}


polymer: drug ratio was varied in each trial, the size distribution did not show significant difference between them ${ }^{21}$.

The formulation EMF5, EMF6 and EMF8 designed by the factorial method, did not produce microparticles by the ionic gelation method, since the ratio of sodium alginate to drug and polymer was not feasible to give required viscosity to the solution to be injected through the insulin needle. So, the microparticles were not formed with required size and rigidity.

in vitro Drug release and its kinetics: Microparticles of all the formulation had slow drug release about $25 \%$ within $1 \mathrm{~h}$. Then the formulations could deliver the drug for a study period of $8 \mathrm{~h}$, the percentage being varied between 68.36$79.77 \%$ at $8 \mathrm{~h}$ (Table-3) based on the polymer: drug ratio in each individual. Even though the percentage of drug release did not show much variation, the formulation EMF1 showed elevated level of drug liberated at the stop time of $8 \mathrm{~h}$ compared to other formulations (Fig. 2). This may be due to superior loading effect, enhanced encapsulation potency and amplified particle size. The mechanism by which drug released from the formulations were verified by fitting the data obtained for in-vitro release studies to various kinetics equations. The $\mathrm{r}^{2}$ value (Table-4) of the optimized formulation EMF1 indicated Higuchi model of release mechanism, which proved a time dependent profile based on diffusion and erosion of the system $^{30}$.

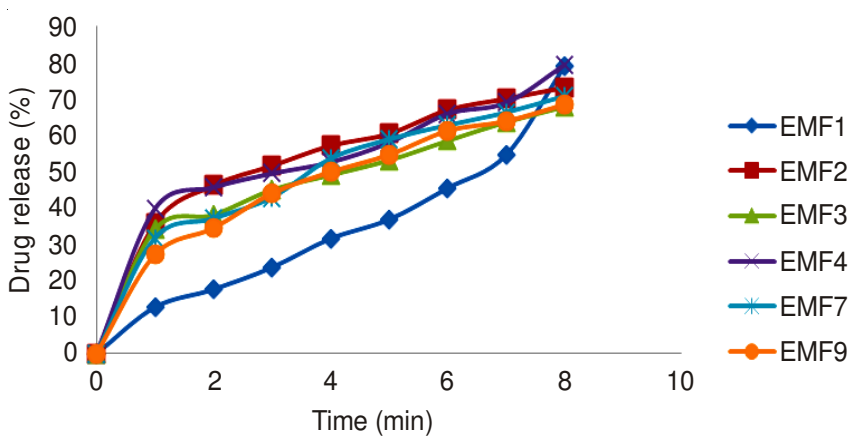

Fig. 2. Comparative in vitro drug release profile of emtricitabine-sodium alginate microparticles

\begin{tabular}{lcccccc}
\multicolumn{7}{c}{ TABLE-4 } \\
\multicolumn{7}{c}{$\begin{array}{c}\text { DRUG RELEASE KINETICS FROM EMTRICITABINE } \\
\text { - SODIUM ALGINATE MICROPARTICLES }\end{array}$} \\
\hline \multirow{2}{*}{ Ratio } & EMF1 & EMF2 & EMF3 & EMF4 & EMF7 & EMF9 \\
\cline { 2 - 7 } & \multicolumn{7}{c}{$\mathrm{r}^{2}$} \\
\hline Zero order & 0.9295 & 0.9699 & 0.9974 & 0.9778 & 0.9757 & 0.9771 \\
First order & 0.8513 & 0.8513 & 0.8513 & 0.8513 & 0.8513 & 0.8513 \\
Higuchi & 0.9923 & 0.9802 & 0.9942 & 0.9878 & 0.9933 & 0.9936 \\
Korsmeyer & 0.9765 & 0.9947 & 0.9672 & 0.9362 & 0.9569 & 0.9918 \\
Hixon & 0.9861 & 0.985 & 0.9947 & 0.9623 & 0.9843 & 0.9952 \\
\hline
\end{tabular}

FT-IR spectra analysis: FTIR spectra of pure drug revealed $^{31}$ its principle peaks of $\mathrm{C}-\mathrm{N}$ stretch at $1154.4 \mathrm{~cm}^{-1}$, $\mathrm{C}=\mathrm{O}$ stretch at $1629.28 \mathrm{~cm}^{-1}$ and $\mathrm{O}-\mathrm{H}$ stretch at $3421.27 \mathrm{~cm}^{-1}$ as shown in Fig. 3. The IR bands of microparticles formulation presented the peaks for both drug and the polymer, in which the corresponding peaks of the drug was found to be less intense, indicating mild interaction between the drug and polymer. The deviation in the wave number and the peak width was observed between the pure drug and the microparticle formulation, which may be due to encapsulation of drug within the polymer by cross linking and hydrogen bonding interactions.
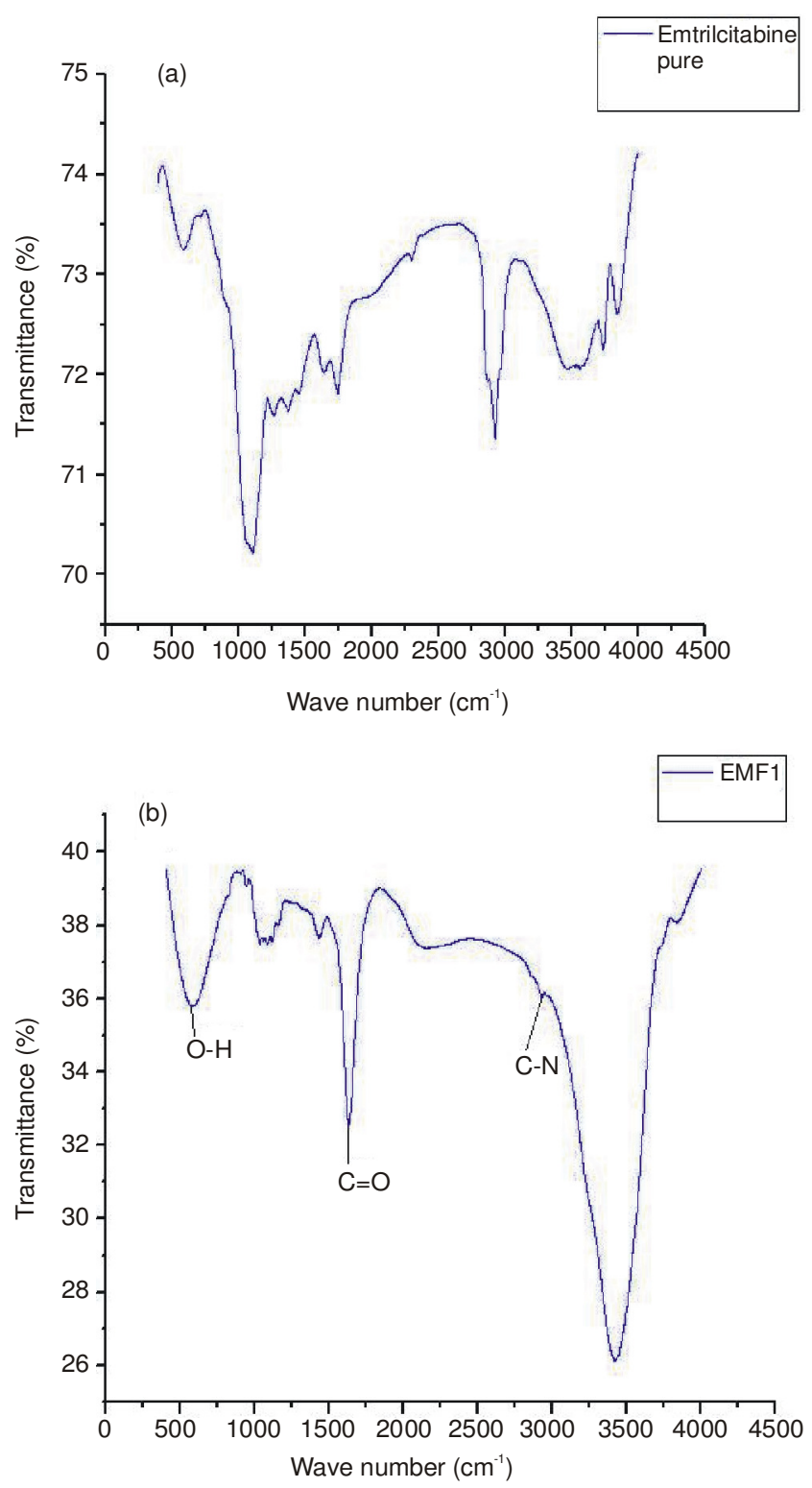

Fig. 3. FTIR spectrum for (a) emtricitabine (pure drug), (b) microparticle formulation (EMF1)

Differential scanning calorimetric analysis: DSC thermogram (Fig. 4) of pure emtricitabine showed a sharp endothermic peak at $153.40^{\circ} \mathrm{C}$ and an exothermic peak at $256.81{ }^{\circ} \mathrm{C}$ indicating its melting point and the decomposition level, respectively ${ }^{31,32}$. The microparticle formulation have shown a shift in the peaks of the drug at $193.25^{\circ} \mathrm{C}$ and $293.13^{\circ} \mathrm{C}$, compared to the pure sample, which was due to the mild interaction of the drug with the polymers during cross linking process. In addition, the peaks of the polymers were observed at $>56^{\circ} \mathrm{C}$ and $>300{ }^{\circ} \mathrm{C}$ for HPMC $\left(68^{\circ} \mathrm{C}\right)$ and sodium alginate $\left(363^{\circ} \mathrm{C}\right.$ and $409^{\circ} \mathrm{C}$ ) respectively ${ }^{33}$, which also was slightly deviated from its normal ranges proving their minimum interaction with the drug. 

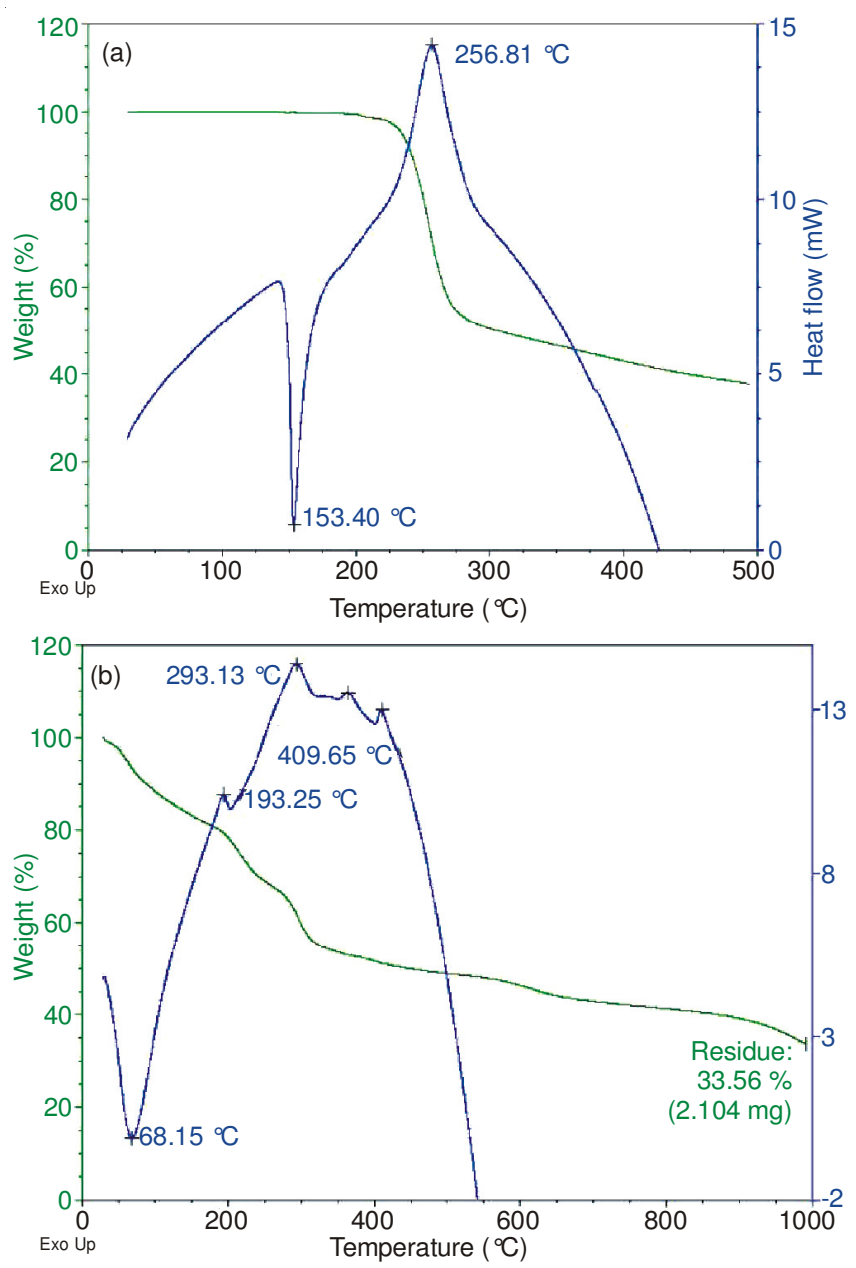

Fig. 4. DSC study for (a) emtricitabine (pure drug) (b) microparticulate formulation (EMF1)

X-ray diffraction study (XRD) analysis: The X-ray diffractogram of pure emtricitabine and its microparticle formulation (EMF1) were showed in Fig. 5. The spectrum of pure emtricitabine confirmed frequent distinct peaks to prove the crystallinity of the drug. No characteristic XRD pattern was observed in the case of drug loaded microparticles, which depicted close intense peaks, due to the semicrystalline or amorphous state modification of the drug and the polymer used. This clearly indicated changes in the crystalline state of the drug occurred during the preparation of the microparticles by the ionotropic gelation method.

Experimental analysis and statistical design: ANOVA was used to carry out the analysis of data and record the responses. The F-test was used to evaluate the individual parameter and a polynomial equation used for multiple linear regression analysis (MLRA). The experimental runs with independent variables and corresponding responses for the 9 formulations are presented in Table-3. The data was fitted with various models of statistical tools like linear, 2FI (two factor interaction), quadratic and cubic for the selected two responses using design expert soft ware (Design 8 Expert TM), it helps to choose the good fit model for better analysis and finally the good fit of the model was evaluated using ANOVA ${ }^{23}$.

$\mathrm{R}^{2}$ (multiple correlation coefficient), adjusted $\mathrm{R}^{2}$ (adjusted multiple correlation coefficient) and PREES (predicted residual sum of square) provided by design-expert software were used
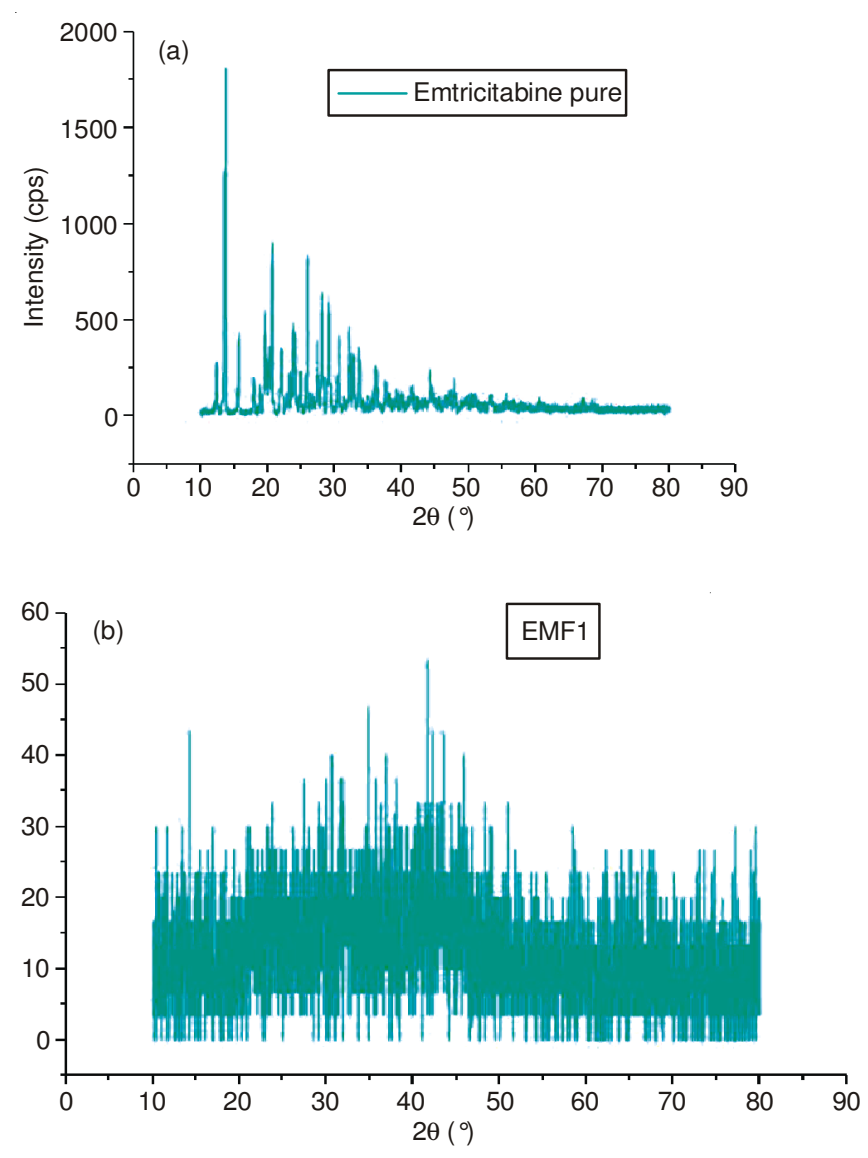

Fig. 5. XRD study for (a) emtricitabine (pure drug), (b) microparticulate formulation (EMF1)

as factors for selection of adequate models. With the above data quadratic model was choosen as a good fit model due to its small predicted residual sum of squares (PRESS) and it gives the quantity of robust model to the points in experiments. For the better data point fit the PRESS must be small.

$$
Y=\beta_{0}+\beta_{1} A+\beta_{2} B+\beta_{3} A B+\beta_{4} A^{2}+\beta_{5} B^{2}
$$

where $\beta_{0}$ is an intercept and $\beta_{1}-\beta_{5}$ are coefficient of respective factors and their interaction response are following,

Response 1: Drug entrapment efficiency (Y1): Value of "Prob > F" was less than 0.0500 which indicate that the model terms were significant. In this case $\mathrm{A}, \mathrm{B}$ and $\mathrm{AB}$ were shown as significant model terms.

$$
\begin{aligned}
\operatorname{Drug} \mathrm{EE}(\mathrm{Y} 1)= & +97.13+0.53 \mathrm{~A}+0.47 \mathrm{~B}-0.068 \mathrm{AB} \\
& +0.63 \mathrm{~A}^{2}-0.69 \mathrm{~B}^{2}
\end{aligned}
$$

Response 1: Drug release (Y2): Value of "Prob > F" was less than 0.0500 which indicate that the model terms were significant. In this case A and B were shown as significant model terms.

$$
\begin{aligned}
\text { Drug release }(\mathrm{Y} 2)= & +72.35-3.78 \mathrm{~A}+1.28 \mathrm{~B}-2.81 \mathrm{AB} \\
& -3.78 \mathrm{~A}^{2}+1.28 \mathrm{~B}^{2}
\end{aligned}
$$

Mathematical relationship in the form of quadric equations for all responses and their standardized main effects are shown in Tables 5 and 6. Positive and negative sign before a coefficient in quadratic models indicate a synergistic effect or an antagonist effect for the factor. The coefficient of $\mathrm{A}, \mathrm{B}$ and $\mathrm{AB}$ 
were significant $(\mathrm{P}<0.05)$. Increasing the concentration of sodium alginate $(\mathrm{B})$ resulted in reduction of drug release. And its interaction terms had a retardation influence on the release of emtricitabine ${ }^{25,26}$.

$3 \mathrm{D}$ response surface and contour plot showing the effect of hydroxy propyl methyl cellulose and sodium alginate on drug entrapment efficiency and percentage drug release showed in Figs. 6 and 7. Drug release was found to be in sustained manner and in a regular fashion as concentration of

(a)

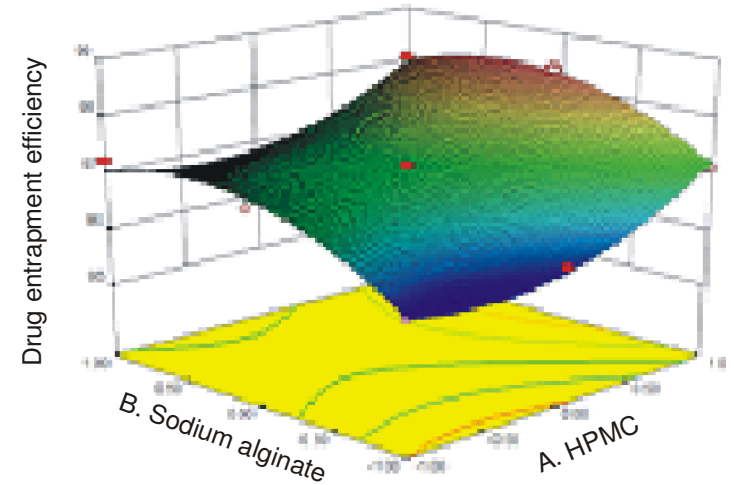

(b)

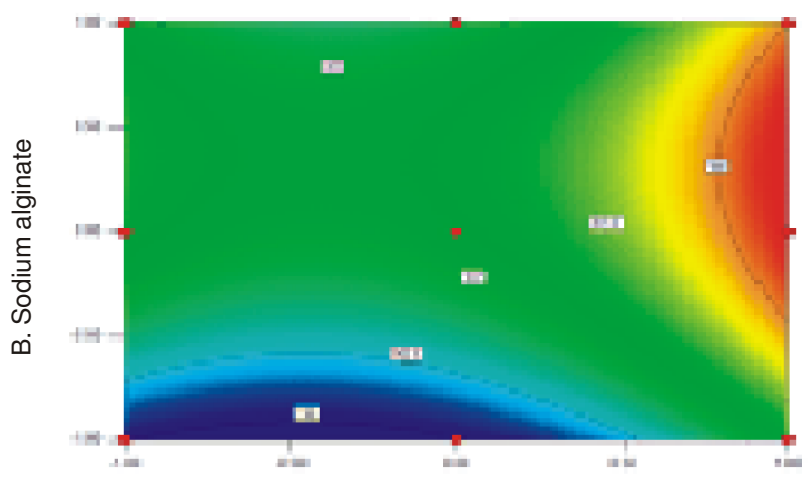

A. HPMC

Figs. 6. (a) 3D Response surface plot and (b) Contour plot showing the effect of the hydroxy propyl methyl cellulose and sodium alginate on drug entrapment efficiency (a)

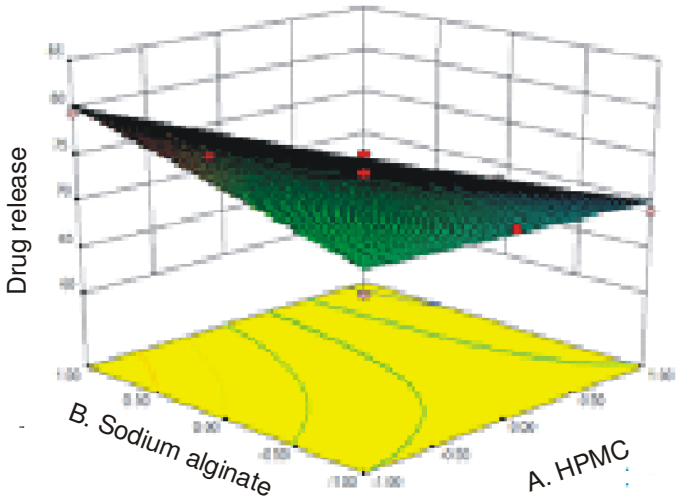

Drug release

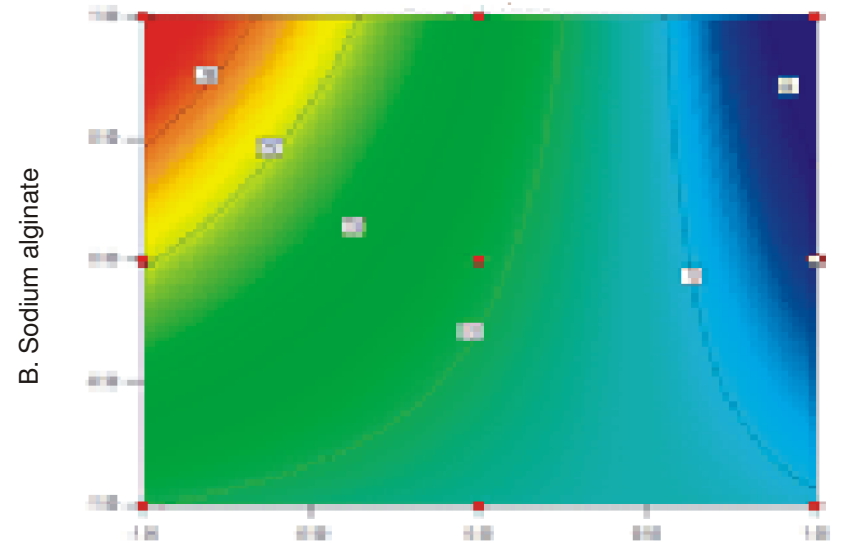

A. HPMC

Fig. 7. (a) 3D Response surface plot and (b) Contour plot showing the effect of the hydroxy propyl methyl cellulose and sodium alginate on percentage drug release

polymer was increased. The optimized formulation was evaluated for drug entrapment efficiency and percentage drug release, Table-7 enlisted the value of the observed and predicted response for the optimized formulation of emtricitabine. The data clearly indicate that the dependent variables were strongly influenced by the independent variables ${ }^{28}$.

\begin{tabular}{lcccccc}
\multicolumn{7}{c}{ ANOVA FOR EMTRICITABINE MICROPARTICLES DRUG ENTRAPMENT EFFICIENCY } \\
\hline Source & SS & DF & MS & F & P & Model significant/ non-significant relative noise \\
\hline Model & 4.78 & 5 & 0.96 & 50.86 & $<0.0001$ & Significant \\
Drug EE & 1.72 & 1 & 1.72 & 91.27 & $<0.0001$ & Significant \\
\% drug release & 1.30 & 1 & 1.30 & 68.95 & $<0.0001$ & \\
Residual & 0.13 & 7 & 0.019 & & & \\
Core total & 4.92 & 12 & & & \\
\hline Drug EE - (Drug entrapment efficiency); DF - degree of freedom, SS - sum of square, MS - mean sum of square, F - Fischer's ratio
\end{tabular}

\begin{tabular}{lcccccc} 
& \multicolumn{7}{c}{ TABLE-6 } \\
& \multicolumn{7}{c}{ ANOVA FOR EMTRICITABINE MICROPARTICLES DRUG RELEASE } \\
\hline Source & SS & DF & MS & F & P & Model significant/ non-significant relative noise \\
\hline Model & 127.38 & 3 & 42.46 & 13.47 & 0.0011 & Significant \\
Drug EE & 85.88 & 1 & 85.88 & 27.25 & 0.0005 & Significant \\
$\%$ drug release & 9.86 & 1 & 9.86 & 3.13 & 0.1108 & \\
Residual & 28.37 & 9 & 3.15 & & & \\
Core total & 155.75 & 12 & & & \\
\hline Drug EE - (Drug entrapment efficiency); DF indicates degree of freedom; SS, sum of square; MS, mean sum of square; and F, Fischer's ratio
\end{tabular}


TABLE-7

PREDICTED AND OBSERVED RESPONSE OF THE OPTIMIZED FORMULATION FOR EMTRICITABINE MICROPARTICLES

\begin{tabular}{cccc} 
Response & Predicted & Observed & Residuals \\
\hline Drug EE & 98.298 & 98.330 & 0.032 \\
$\%$ Drug release & 80.227 & 79.420 & -0.807 \\
\hline
\end{tabular}

Drug EE - (Drug entrapment efficiency); Residual = observed value predicted value

\section{Conclusion}

Sustained release microparticles of water soluble drug emtricitabine using anionic polymer can be successfully prepared by ionic gelation method with better yield of production, higher content of drug and improved potency of encapsulation. All the microparticles demonstrate definite morphology (smooth surface) and unique dimensional characteristics (spherical shape) with fine size range divisions. From FTIR, DSC and XRD, it could be revealed that Emtricitabine microparticle formulation demonstrated less significant interaction within the polymers used. The in vitro release studies proved the typical sustained release of drug for more than $8 \mathrm{~h}$. The application of $3^{2}$ factorial design was very useful for optimization of emtricitabine microparticles. The data so obtained clearly indicate that the particle size, drug content, encapsulation property variables were strongly influenced by the changes in ratio of the drug and polymers variables. This dosage form ensures sustained release of the water soluble drug which can extend the interval of action, circumvent early dose clearance.

\section{ACKNOWLEDGEMENTS}

The authors are grateful to the Management of SASTRA University for providing the necessary infrastructure and support to complete this work successfully.

\section{REFERENCES}

1. N.P. Abhay, R.S. Sadhana and W.T. Mahesh, Int. J. Pharm. Res. Dev., 3, 99 (2011).

2. M.N.V. Satheesh and K. Shivani, Int. J. PharmTech. Res., 3, 1242 (2012).

3. D.L. Wise, Handbook of Pharmaceutical Controlled Release Technology, CRC Press, New York, p. 271 (2000)
4. R. Langer and J. Folkman, Nature, 263, 797 (1976).

5. S.D. Putney and P.A. Burke, Nat. Biotechnol., 16, 153 (1998).

6. J. Moore, The Drug Delivery Outlook to 2005, Business Insights Ltd., (1999).

7. J. Siepmann, Prog. Colloid Polym. Sci., 15, 133 (2006).

8. http://www.drugs.com/sfx/atripla-side-effects.html.

9. P. Emillio, Archive of SID, 8, 125 (2008).

10. J.E. Gallant, E. DeJesus, J.R. Arribas, A.L. Pozniak, B. Gazzard, R.E. Campo, B. Lu, D. McColl, S. Chuck, J. Enejosa, J.J. Toole and A.K. Cheng, N. Engl. J. Med., 354, 251 (2006).

11. K.D. Malay and C.S. Prakash, Acta Polon. Pharm. Drug Res., 64, 253 (2007).

12. C.M. Silva, A.J. Ribeiro, M. Figueiredo, D. Ferreira and F. Veiga, AAPS J., 7, 903 (2005).

13. R.W.J. Lencki, R.J. Neufeld and T. Spinney, US Patent 4822534 (1989).

14. K. Nilsson, S. Bimbaum, S. Flygare, L. Linse, U. Schroder, U. Jeppsson, P.O. Larsson, K. Mosbach and P. Brodelius, Eur. J. Appl. Microbial. Biotechnol., 17, 319 (1983).

15. L.S.C. Wan, P.W.S. Heng and L.W. Chan, J. Microencapsul., 9, 309 (1992).

16. V. Belgamwar, V. Shah and S. Surana, Curr. Drug Deliv., 6, 113 (2009).

17. P. Venkatesan, R. Manavalan and K. Valliappan, J. Pharm Sci. Res., 1, 26 (2009).

18. B.N. Vedha Hari, A. Brahma Reddy and B. Samyuktha Rani, J. Young Pharmacists, 2, 350 (2010).

19. J. Luypaert, M.H. Zhang and D.L. Massart, Anal. Chim. Acta, 478, 303 (2003).

20. S. Roy, S.G. Panpalia, B.C. Nandy, V.K. Rai, L.K. Tyagi, S. Dey and K.C. Meena, Int. J. Pharm. Sci. Drug Res., 1, 36 (2009).

21. B.C. Gangadhar, R.S. Sunder, M.V. Vimal Kumar, M.S. Raju and M.S. Kiran, Int. J. Drug Discovery, 2, 8 (2010).

22. L. Pachuau and B. Mazumder, Int. J. PharmTech Res., 1, 966 (2009).

23. L. Pachuau, S. Sarkar and B. Mazumder, Trop. J. Pharm. Res., 7, 995 (2008).

24. H. Eroglu, R. Alpar and L. Toner, J. Pharm. Sci., 33, 144 (2008).

25. P.D. Chudiwal, P.L. Pawar, M.A. Nagaras and S.K. Mandlik, S.V. Pandya and P. Wakte, Int. J. PharmTech Res., 1, 1366 (2009).

26. J. Shaji and A. Shinde, Int. Res. J. Pharm., 3, 166 (2012).

27. G. Deshmukh, D. Ruikar, A.K.Seth, T. Ghelani, H. Patel, J. Patel and J. Patel, Pharm. Sci. Monitor: Int. J. Pharm. Sci., 2, 26 (2011).

28. S.C. Jagdale, S.A. Ghorpade, B.S. Kuchekar and A.R. Chabukswar, Int. J. Pharm. Applications, 3, 181 (2011).

29. A.V. Pande, U.A. Nimbalkar, M.V. Dhoka and P.A. Sonawane, Int. J. Res. Pharm. Chem., 1, 448 (2011).

30. G. Singhvi and M. Singh, Int. J. Pharm. Studies Res., 2, 77 (2011).

31. http://www.drugbank.ca/drugs/DB00879.

32. I.A. Kartsonakis and G. Kordas, J. Am. Ceram. Soc., 93, 65 (2010).

33. T. Phaechamud, A. Mesnukul and K. Yodkhum, Indian J. Pharm. Sci., 71, 413 (2009). 